\title{
Preliminary Study on Epoxidized Natural Rubber Latex Composites Intended for Shoe Soles Application
}

\author{
Roslim Ramli ${ }^{1,2}$, Chai Ai Bao ${ }^{2}$, Fatimah Rubaizah Mohd. Rasdi ${ }^{1}$, Shamsul Kamaruddin ${ }^{1}$, Azira Abd. Aziz ${ }^{1}$, \\ Tan Kim Song ${ }^{1}$, Mok Kok Lang ${ }^{1}$ and Ho Jee Hou ${ }^{2}$ \\ ${ }^{1}$ Technology and Engineering Division, Malaysian Rubber Board, Sg. Buloh, 47000 Selangor, Malaysia, \\ ${ }^{2}$ Faculty of Science and Engineering, University of Nottingham Malaysia, Semenyih, 45300 Selangor, Malaysia.
}

\begin{abstract}
Epoxidized natural rubber (ENR) is a well-known rubber material exhibits high-damping and better wet-grip compared to normal NR, but its applications are relatively limited and found only in dry rubber sector. This study aims to diversify the application of ENR by introducing it into latex-based products. In this study, ENR latex is prepared via an in-situ epoxidation reactions, followed by ultrafiltration process using membrane separation technology. The prepared ENR latex concentrate exhibits higher mechanical stability time and different viscosity properties compared to commercially available HA latex concentrate. Both ENR latex and HA latex concentrates are compounded via sulphur pre-vulcanisation process and cast into latex films. Although both latexes are compounded at a similar level of vulcanising agents, HA latex films are found to be higher in crosslink density and tensile strength compared to ENR latex films. Addition of nanomaterial slightly increases the crosslink density and tensile strength of both films, but the overall improvement of physical properties was not distinctly discriminative. The presence of nanomaterial also improves the electrical conductivity property of both films. Transmission Electron Microscopy visualized poor distribution of the nanomaterial in the rubber matrix, limiting the reinforcing effect of the nanomaterial, as well as the effectiveness to impart the electrical conductivity. Nevertheless, the study found that the ENR latex concentrate is a suitable material for fabrication of shoe soles, and potentially be used as an alternative material for better wet-grip and damping property.
\end{abstract}

Key words: Epoxidized Natural Rubber Latex, Composites, Shoe Soles.

\section{INTRODUCTION}

Natural rubber (NR) latex is a natural and sustainable industrial material harvested from rubber tree known as Hevea brasiliensis [1]. NR latex has become material of choice for many dipped goods such as gloves, condoms, catheters, balloons etc. due to its elasticity, durability and being natural and biodegradable material [2],[3]. Currently, there are two main types of NR latex that are used to manufacture NR latex products, namely high ammonia (HA) latex and low ammonia (LATZ) latex. However, there are also other forms of NR latex known as specialty NR latex, such as epoxidized natural rubber (ENR) latex which is produced to meet the specific requirements of products and consumers. ENR is a well-known rubber material exhibits high-damping, excellent wet-grip and better oil and chemicals resistance compared to normal NR [28]. Despite their niche properties, product applications of ENR are relatively limited. ENR is used normally in the form of bulk rubber to make dry rubber products such as tires and automotive parts. To date, there is not much information concerning utilization of ENR latex in latex based products.

Currently, Malaysian Rubber Board (MRB) has produced a new generation of ENR latex known as EKOPRENA ${ }^{\circledR}$ latex [28]. This ENR latex is produced by epoxidation of field NR latex at $50 \%$ mol epoxidation levels. In addition, this ENR latex is intentionally concentrated to $60 \%$ total solid content (TSC) through a patented membrane separation process (Patent No. PI 2017700457, 2017). The availability of concentrated ENR latex has provided a better opportunity to diversify the application of ENR latex into moulded latex products. This is because high concentration of latex will give lower volume shrinkage, which is important in manufacturing moulded latex products. The present study explores the feasibility of compounding ENR latex through sulphur pre-vulcanisation process. The compounded ENR latex is cast into continuous latex films through conventional practice i.e. the pour and let-dried in a mould method. In this work, the physical properties and the crosslinks density of the cast latex films becoming the focal points. In addition, this study hypothesises that the properties of ENR latex films could be further enhanced by incorporating small amount of nanomaterials into the ENR latex compound. Therefore, the effectiveness of different types and levels of nanomaterials loading on physical properties and crosslinks density of the cast ENR latex films were investigated. Due to electrical conductivity property offered by some of the nanomaterials, 
the degree of electrical conductivity of the ENR latex composites were examined. In addition, in order to assess the influence of epoxy group in ENR rubber chains or polarity of ENR latex on compatibility of ENR latex with nanomaterials used in this study, normal high ammonia NR (HA) latex composites were prepared in the similar conditions for comparative study.

Further to that, due to huge global market value and demand for natural-based or environmentally-friendly materials in footwear industries [4]-[6], this study explores the feasibility of developing shoes sole from ENR latex compound. Owing the fact that ENR is a material with high-damping and excellent wet-grip properties, successful development of shoe soles from ENR latex not only offers environmentally-friendly image but shoe soles with high-damping and excellent wet-grip properties. In addition, the possibility of producing ENR latex cast film with electrical conductivity property in the present study provides an opportunity for developing anti-static shoe soles for a wider range of applications.

\section{MATERIALS AND METHODS}

\subsection{Preparation of ENR Latex Concentrate}

ENR latex was prepared in accordance to common process and formulation described elsewhere [7]-[9]. The process involves in-situ chemical reactions of hydrogen peroxide and formic acid which substitutes the double bond structure to generate epoxy group onto the rubber molecular chains. However, in this study, field NR latex was used as the raw material for producing ENR latex. The resultant ENR latex was then subjected to ultrafiltration process using membrane separation technology to increase the ENR latex concentration from $30 \%$ total solid content (TSC) from $30 \%$ to $60 \%$. In general, field NR latex was stabilized first with a non-ionic surfactant, containing fatty alcohol ethoxylated groups. The mixture was stirred for 30 minutes to obtain homogenous mixture. Then, an assigned amount of formic acid $(\mathrm{HCOOH})$ and hydrogen peroxide $\left(\mathrm{H}_{2} \mathrm{O}_{2}\right)$ were added into the stabilized field NR latex. Subsequently, the field NR latex was heated at $45^{\circ} \mathrm{C}$ for an hour, $50{ }^{\circ} \mathrm{C}$ for 3 -hour and 60 ${ }^{\circ} \mathrm{C}$ for 24-hour for epoxidation reactions to take place. Once the targeted epoxidation was achieved, the epoxidation reaction was terminated by neutralising the latex using ammonia $\left(\mathrm{NH}_{3}\right)$ until $\mathrm{pH}$ 7. The production of the ENR latex concentrate involve continuously pumping the preserved ENR latex into a series or parallel ultrafiltration membrane arrangement according to the method patented in Malaysian patent filling number PI2017700457 (Patent No. PI 2017700457, 2017). The ENR latex concentrate was kept at room temperature for a month to improve homogeneity before further testing.

\subsection{Determination of Physiochemical Properties of ENR Latex Concentrate}

\subsubsection{Determination of Latex Chemical Properties Using RRIMETER $^{\circledR}$}

In this work, modern and fast technology developed by MRB known as RRIMETER ${ }^{\circledR}$ was used. The determination of dry rubber content (DRC), total solid content (TSC) and alkalinity $\left(\mathrm{NH}_{3}\right)$ was done according to MRB in-house method developed through calibration and comparison between the standard latex testing method [10]. Approximately $20 \mathrm{~mL}$ of latex was poured in the RRIMETER container and placed in the RRIMETER slots. DRC, TSC and alkalinity values of the latex were analysed automatically using the instrument. DRC, TSC and alkalinity values obtained through this technique were recorded accordingly.

\subsubsection{Determination of Epoxidation Level via ${ }^{1} \mathrm{H}$ Nuclear Magnetic Resonance}

The determination of ENR structure using ${ }^{1} \mathrm{H}-\mathrm{NMR}$ method was developed by Durbetaki and Miles [11],[12]. The epoxy group content of ENR was estimated from the intensity ratio signals Equation (1). In this work, Bruker AMX 400 Wide Bore nuclear magnetic resonance (NMR) spectrometer $(1 \mathrm{H}=$ $400 \mathrm{MHz}$ ) was used to perform the analysis. An in-house method developed by MRB [13] was followed.

$\operatorname{Mol}(\%)$ epoxide $=\frac{(\text { epoxy methane })}{(\text { epoxy methane })+(\text { olefinic })} \times 100 \%$

\subsubsection{Determination of Nitrogen Content}

Nitrogen content is a measure of deproteinization level of DPNR latex. The nitrogen content was determined in accordance to Kjeldahl method [27]. The percent of nitrogen was calculated according to Equation (2):

Nitrogen $(\%)-\frac{\left(V_{1}-V_{2}\right) \times N \times 0.014}{\text { welghr of sample }} \times 100 \%$

Where $V_{l}$ is the volume of sulphuric acid required for titration of the contents in the conical flasks, $V_{2}$ is the volume of sulphuric acid required for titration of the blank, $N$ is the normality of the sulphuric acid.

\subsubsection{Viscosity Measurement}

The viscosity of latex was measured after the specified time periods using Brookfield viscometer (model LVF) with spindle No. 2 at 60 r.p.m. in accordance to ISO 1652:2011 standard method [14]. 
Roslim Ramli et al., International Journal of Emerging Trends in Engineering Research, 8(1.2), 2020, 122- 131

\subsubsection{Mechanical Stability Time Measurement}

The mechanical stability time (MST) was examined using KLAXON latex stability test machine in accordance to ISO 35:2004 standard method [15].

\subsection{Preparation of ENR latex compound and cast film}

The vulcanising ingredients includes $60 \%$ TSC sulphur dispersion, $50 \%$ TSC zinc diethyl dithiocarbamate (ZDEC) dispersion, $50 \%$ TSC zinc dibutyl dithiocarbamate (ZDBC) dispersion, $50 \%$ TSC zinc-2-mercaptobenzothiazole (ZMBT) dispersion, $50 \%$ TSC antioxidant dispersion and $60 \%$ TSC zinc oxide $(\mathrm{ZnO})$ dispersion that were purchased from Alpha Nano Technology Sdn. Bhd.

Table 1: Information on nanomaterials used in this study

\begin{tabular}{|c|c|l|}
\hline No & Trade name & \multicolumn{1}{|c|}{ Description } \\
\hline 1 & $\begin{array}{c}\text { DYNASYLAN } \\
\text { GLYEO }\end{array}$ & $\begin{array}{l}\text { Water-based bifunctional } \\
\text { organosilane solution }\end{array}$ \\
\cline { 3 - 3 } & 3-Glycidyloxypropyltriethoxysilane \\
\hline 2 & $\begin{array}{c}\text { AERODISP W } \\
7520\end{array}$ & $\begin{array}{l}\text { Aqueous dispersion of hydrophilic } \\
\text { fumed silica }\end{array}$ \\
\hline 3 & $\begin{array}{c}\text { AVANZARE } \\
\text { AVANSTATIC } \\
75 \text { B }\end{array}$ & $\begin{array}{l}\text { Water-based inorganic antistatic } \\
\text { nanofiller solution }\end{array}$ \\
\hline 4 & MWCNT & $\begin{array}{l}\text { Multi-wall carbon nanotubes } \\
\text { dispersion }\end{array}$ \\
\hline
\end{tabular}

The stabilizer used in this study was a $17.5 \%$ potassium oleate solution that was purchased from Aquaspersions (M) Sdn. Bhd. For nanomaterials, fumed silica dispersion (AERODISP $^{\circledR}$ W 7520), organosilane solution (DYNASYLAN GLYEO $^{\circledR}$ ), and inorganic antistatic nanofiller solution (AVANZARE AVANSTATIC $75 \mathrm{~B}^{\circledR}$ ) were supplied by Jebsen \& Jessen Ingredients (M) Sdn. Bhd., whilst multi-wall carbon nanotubes (MWCNT) was purchased from KD Land Sdn. Bhd. Table 1 summarise the information for the nanomaterials used in this study.

The ENR latex concentrate was compounded in accordance to the formulation shown in Table 2. Potassium oleate was added first into the ENR latex. The vulcanising ingredients were mixed first and left at room temperature for 15 minutes before added into the ENR latex. The compounded ENR latex was left at room temperature for 16 hours for maturation.

After that, the nanomaterials used in this study were added slowly into the compounded ENR latex, while the latex was being stirred at 45 r.p.m. It should be noted that, the concentration of each nanomaterials was not disclosed by the supplier. Therefore, for specific purpose of the study, each of nanomaterials was loaded into the compounded ENR latex at $1.25 \%, 2.5 \%, 5 \%$ and $10 \% \mathrm{w} / \mathrm{w}$ of dispersion as received.
The ENR latex mixture was left for 60 minutes to improve homogeneity. Then, the ENR latex mixture was poured onto a cast plate with target thickness of $0.25 \mathrm{~mm}$ and $0.5 \mathrm{~mm}$ for physical properties measurement and electrical conductivity measurement respectively. The ENR latex mixture was left to dry at room temperature overnight to produce continuous film before the film was peeled off, and followed by immersing in tap water for overnight leaching process. Then, the ENR latex film was heated in a hot air oven at $100{ }^{\circ} \mathrm{C}$ for 30 minutes to allow vulcanisation process to take place. For comparative study, HA latex films also were prepared in a similar condition. All samples were kept dry in a desiccator for at least 16 hours before testing.

Table 2: Compounding formulation used in this study

\begin{tabular}{|l|c|c|}
\hline \multicolumn{1}{|c|}{ Ingredient } & $\begin{array}{c}\text { TSC } \\
(\boldsymbol{\%})\end{array}$ & $\begin{array}{c}\text { Dry weight } \\
\text { (p.h.r.) }\end{array}$ \\
\hline EKOPRENA latex & 60 & 100 \\
\hline Potassium oleate & 17.5 & 1 \\
\hline Sulphur dispersion & 60 & 2.5 \\
\hline Zinc oxide dispersion & 60 & 0.2 \\
\hline ZDEC dispersion & 50 & 1 \\
\hline ZDBC dispersion & 50 & 0.5 \\
\hline ZMBT dispersion & 50 & 0.5 \\
\hline Antioxidant dispersion & 50 & 1 \\
\hline
\end{tabular}

\subsection{Crosslink density measurement}

The effective crosslink concentration $\left(\eta_{\text {phys }}\right)$ of the sample was determined from equilibrium swelling measurement using Flory Rehner equation (Equation 3). Method suggested by previous study (Roslim, 2015) was followed.

$-\left[\ln \left(1-V_{r}\right)+V_{r}+\mathrm{sV}_{r^{2}}{ }^{2}\right]-2 \rho V_{0} \eta_{p \mathrm{~L}_{y s}} V_{r^{2}}^{1 / 8}$

Where $V_{r}$ is the equilibrium volume fraction of rubber in swollen gel, $\rho$ the density of rubber, $V_{o}$ the molar volume of the swelling liquid and $X$ an interaction constant characteristic of rubber and swelling liquid and $\eta_{p h y s}$ is the concentration of physically effective crosslink.

\subsection{Physical Properties Measurement}

The physical properties of the latex films were measured in accordance to ISO 37 standard method [16] using Instron machine at Physical Testing Laboratory, MRB. The test sample was pulled at $500 \mathrm{~mm} \pm 50 \mathrm{~mm}$ per min at a constant rate. 
Roslim Ramli et al., International Journal of Emerging Trends in Engineering Research, 8(1.2), 2020, 122- 131

\subsection{Electrical conductivity measurement}

The surface resistivity of the latex films was measured in accordance to ISO 14309 standard method [17] using Keithley 6517B at Physical Testing Laboratory, MRB. The current voltage was $500 \mathrm{~V}$.

\subsection{Morphological Structures Visualization}

In this work, FEI G2 F20 Transmission Electron Microscopy (TEM) and Leica U600 ultra-microtome were used to visualise the intrinsic structure of the films [18]. The latex film was cut into small piece and attached onto the ultra-microtome holder. The test sample was freeze at $-90{ }^{\circ} \mathrm{C}$ using liquid nitrogen. Glass knives were used for trimming and sectioning process. The rubber sections were collected onto TEM examination grid. The rubber mesh structure was visualized using TEM whereas electron beams was transmitted through the rubber sections at $200 \mathrm{kV}$. The images obtained from TEM were analysed for morphological study.

\subsection{Fabrication Shoe Soles}

The shoe soles mould was designed and fabricated at Engineering and Prototyping Laboratory, MRB. The compounded ENR latex was poured into shoe soles mould and left to dry at room temperature overnight. Then, the moulded shoe soles were peeled off the mould and transferred to a room temperature water tank for overnight leaching before subjected to the vulcanizing process in a hot air oven at temperature of $100^{\circ} \mathrm{C}$ for 30 minutes.

\section{RESULTS AND DISCUSSIONS}

\subsection{Physiochemical Properties}

Table 3 shows physicochemical properties of HA and ENR latex concentrates used in this work. The epoxidation level of ENR latex concentrate was found at $48 \%$ mol, slightly lower than the targeted epoxidation value. However, the membrane separation technique successfully achieved the targeted TSC and DRC value of ENR latex concentrate which are $66 \%$ and $65 \%$ respectively. The results also show that, nitrogen content and Mooney viscosity of ENR latex concentrate are lower than HA latex. But MST and flow viscosity ENR latex exhibits higher value compared to HA latex. The high MST and flow viscosity of ENR latex concentrate could be due to high level of surfactant presence in the latex system. The surfactant not only used as stabilizer during epoxidation process but also during membrane separation process. This surfactant able to minimizes shear stress effect by enveloping outer layer of the rubber particles, thus increasing the MST value but tend to decrease the fluidity of the latex.
Table 3: The physiochemical properties of HA and ENR latex used in this study

\begin{tabular}{|l|c|c|}
\hline \multicolumn{1}{|c|}{ Parameters } & $\begin{array}{c}\text { HA } \\
\text { latex }\end{array}$ & $\begin{array}{c}\text { EKOPRENA } \\
\text { latex }\end{array}$ \\
\hline TSC (\%) & 61 & 66 \\
\hline DRC (\%) & 60 & 65 \\
\hline Alkalinity (\%) & 0.66 & 0.45 \\
\hline Nitrogen content (\%) & 0.29 & 0.15 \\
\hline MST (sec) & 1380 & 1800 \\
\hline Viscosity (Cps) & 70 & 500 \\
\hline Epoxidation level (\%) & NA & 48 \\
\hline
\end{tabular}

3.2 Crosslink Density

In this study, HA latex film exhibits higher crosslink density value compared to ENR latex film (Figure 1). This implies that, at similar level of sulphur introduced into both HA and ENR latex during compounding process, a greater number of crosslinking formed in HA latex film compared to ENR latex film. This could be due to the presence of epoxy groups in the ENR rubber chains, which limiting the extend of the sulphur crosslinking in the rubber matrix [18]-[20].
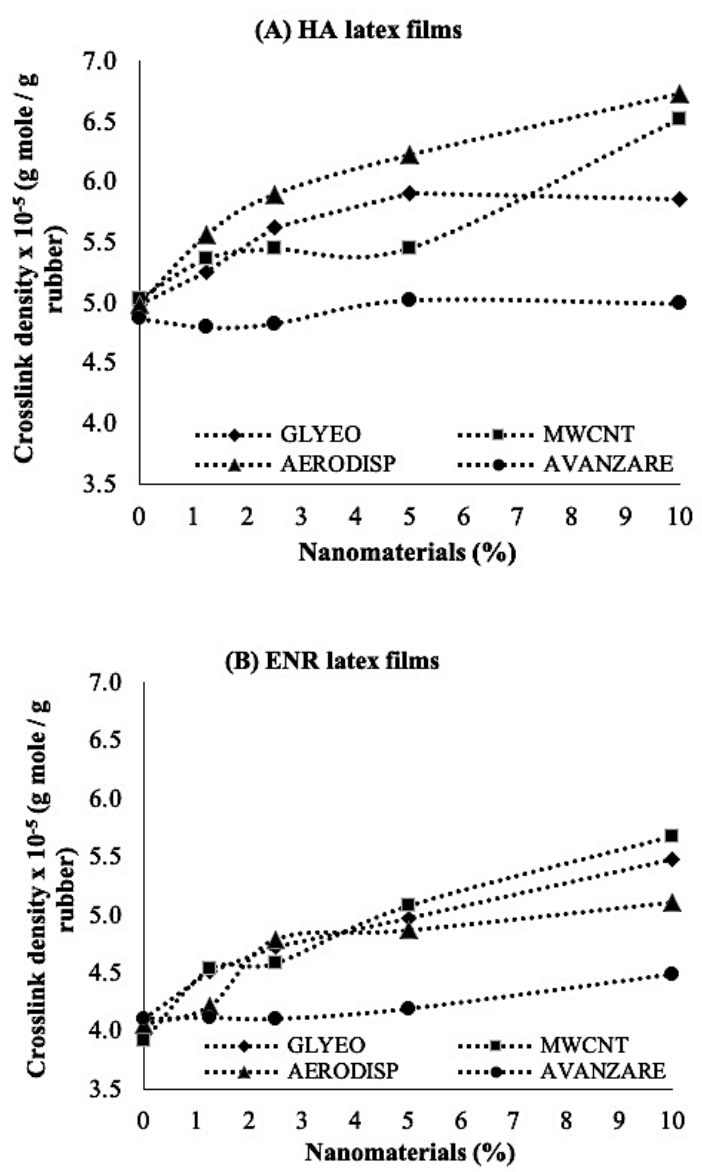

Figure 1: Crosslink density of HA and ENR latex films 
This study also found that incorporation of nanomaterials into the latex compound increases the crosslink density value of both HA and EKOPRENA latex films. Nevertheless, the increment in the crosslink density value by incorporating nanomaterials not necessarily due to formation of crosslinks in the rubber matrix. This is because the presence of filler may retard the swelling of rubber particles by the solvent, inhibiting the accuracy of measurement of actual physical crosslink introduced in the rubber matrix. Yet, the present study found dissimilarity effect of nanomaterials on HA and ENR latex films. For HA latex, incorporation of AERODISP shows the greatest improvement on crosslink density value followed by GLYEO, MWCNT and AVANZARE. But, for ENR, MWCNT shows the greatest improvement on crosslink density value followed by GLYEO, AERODISP and AVANZARE. This could be due to different chemical characteristics of nanomaterials used in this study which influence compatibility between nanomaterials and the ENR and HA chemical properties.

\subsection{Physical Properties}

Figure 2 shows M300 of HA and ENR latex examined in this study. Unexpectedly, ENR latex films exhibit higher M300 value than HA latex films. This is contradicting with crosslink density measurement shows in Figure 1, whereas crosslink density of HA latex films was higher than ENR latex films. One possible reason for this result is due to epoxy group in ENR latex which increases the stiffness of the films. This study also found that, except AVANZARE, incorporation of nanomaterials increased the M300 value of both HA and ENR latex films. Similar to crosslink density, AERODISP shows the best reinforcing filler for HA latex films, whilst for ENR latex films, MWCNT shows a consistent improvement of M300 value as the levels of MWCNT loading were increased. The decrement of M300 value of ENR latex films when the concentration of AVANZARE was increased is not clear and required further investigation.

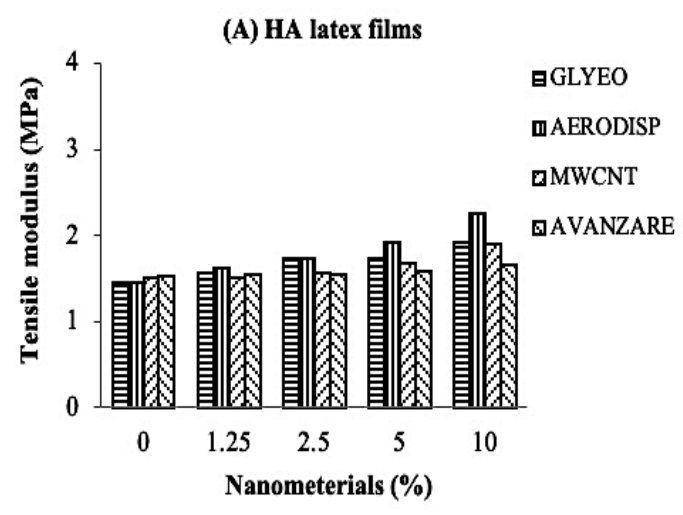

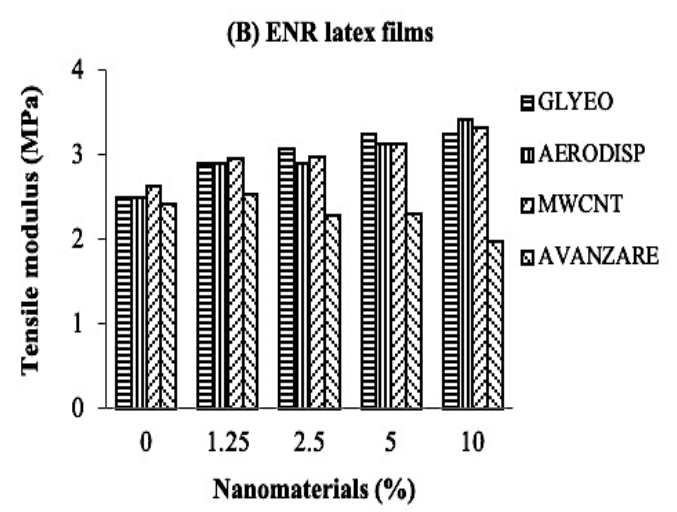

Figure 2: Tensile modulus of (A) HA and (B) ENR latex

Figure 3 demonstrates that, the cast latex films seemed to have a slight uptrend on TS value of films loaded with nanomaterials but the overall performance was not distinctly discriminative. The extraordinary properties and high surface area and aspect ratio of nanomaterials are expected to show tremendous improvement on strength property of both HA and ENR latex films. This unexpected result could be due to insufficient integration between nanomaterials and rubber particles to provide cohesive rubber-filler network. Previous study [20],[21] stated that, poor physical strength enhancement of NR latex films when loaded with nanomaterials could be due to poor mixing route of nanomaterials into the colloidal NR latex system.

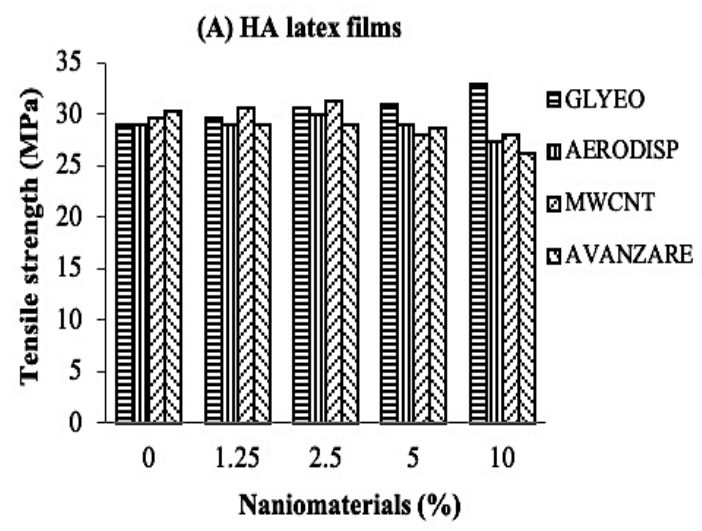

(B) ENR latex films

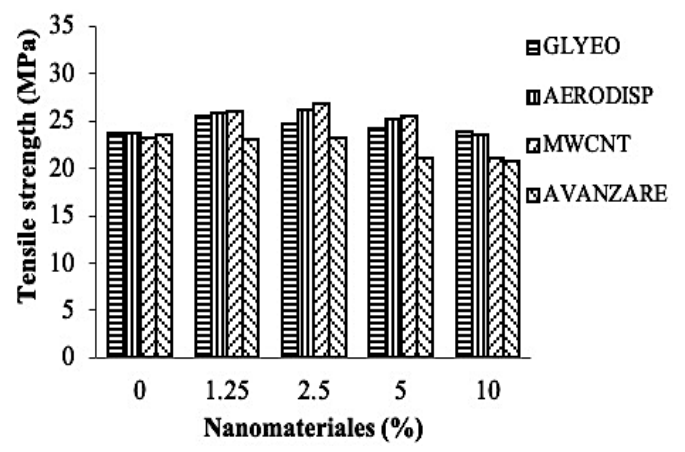

Figure 3: Tensile strength of HA and ENR latex films 
In the present study, the nanomaterials were incorporated into the latex compound through conventional stirring process. Therefore, this ineffective mixing process could lead to agglomeration of the nanomaterials into the rubber matrix [21]. Thereby, the increment of strength property of the film was not distinctly significant. Nevertheless, comparative study between HA and ENR latex films indicated that HA latex films exhibit higher TS value compared to ENR latex films. For HA latex films, GLYEO was observed to show consistent improvement on TS value compared to other nanomaterials. On the other hand, for ENR latex films, MWCNT shows the best reinforcing nanomaterials. This study also found that, except for GLYEO in HA latex, addition of nanomaterials into both HA and ENR latex compound beyond $5 \%$ tended to reduce TS value. This could be due to the extent of stiffness of the latex films which affect the degree of crystallization of rubber during stretching [18],[20] or could be due to the presence of agglomerated nanomaterials which formed clusters in the rubber matrix. These non-elastic clusters contribute to flaws in the latex by inducing stress points [22]. It is thought that shape of the nanomaterials and the manner each nanomaterial interacted with the rubber matrix within the latex film affected its physical properties. Further to that, the formation of cluster may affect the degree of crosslink formation typically poly-sulphidic crosslinks at dry stage, and thus reduce the strength property of the films [18].

The effect of nanomaterials on HA and ENR latex films after ageing was investigated. Figure 4 shows that, HA latex films demonstrate better aging resistant compared to EKOPRENA latex films. However, in the presence of nanomaterials, TS value of ENR latex films was remarkable increased, especially when loaded with higher levels of nanomaterials. On the other hand, for HA latex films, only MWCNT shows increment in TS value.

\section{(A) HA latex films}

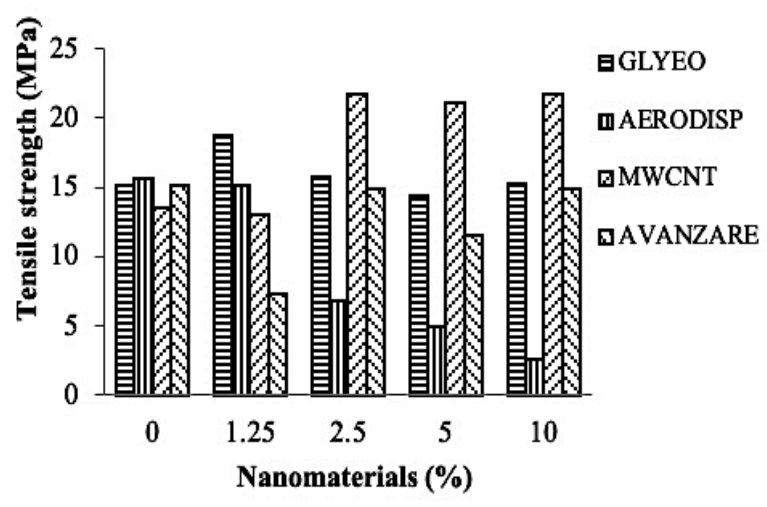

(B) ENR latex films

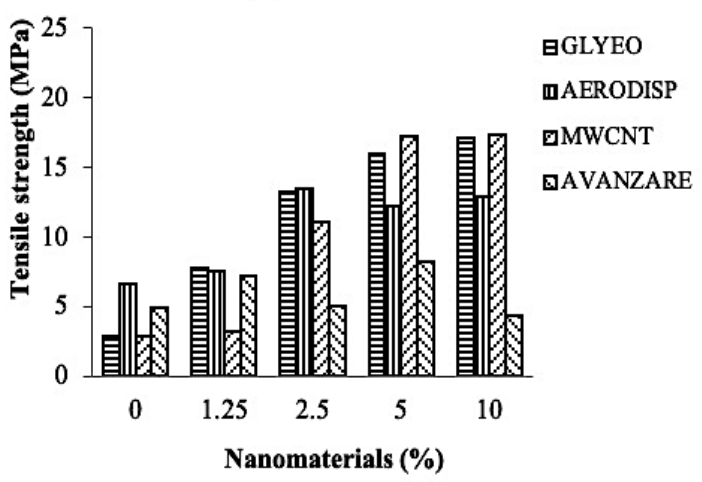

Figure 4: Tensile strength of HA and ENR latex films after ageing

\subsection{Electrical Conductivity}

\subsubsection{Surface resistivity}

Surface resistivity is the resistance to leakage current along the surface of an insulating material. The higher the surface resistivity, the lower the leakage current and the less conductive the material is [23],[24]. Figure 5 shows surface resistivity of HA and ENR latex films loaded with nanomaterials used in this study. It is clear that, without nanomaterials, both HA and ENR latex films exhibit insulative property. However, comparison between HA latex films (Figure 5A) and ENR latex films (Figure 5B) shows that HA latex films exhibits higher surface resistivity than ENR latex films. This could be due to the presence of epoxy group in ENR rubber chains which increase the mobility or charge carriers [25]. In the presence of nanomaterials, the surface resistivity value tends to reduce. Interestingly, this study found that addition of nanomaterials into ENR latex films show greater decrement of the surface resistivity value compared to addition of nanomaterials into HA latex films. Surface resistivity value was observed to achieve anti-static characteristic $\left(1 \times 10^{\wedge}-1 \times 10^{\wedge}{ }^{12}\right)$ when ENR latex film loaded with GLYEO. ENR latex film loaded MWCNT also show improvements in surface resistivity value. As shown in Figure 5B, ENR latex film achieved antistatic property when loaded with $1.25 \%$ of GLYEO, which is not happen in HA latex film. However, the surface resistivity value dramatically decreased when the levels of GLYEO was increased to $2.5 \%$, $5 \%$ and $10 \%$. This study also observed that, ENR latex films loaded with $2.5 \%$ of MWCNT shows lowest surface resistivity value. Further to that, ENR latex film loaded with $10 \%$ of AVANZARE also exhibits antistatic property. For HA latex films, only the film loaded with $2.5 \%$ of MWCNT shows antistatic property. Further increase in the percentage of MWCNT in HA latex should reduce the surface resistivity value, but it was opposite. Previous study [26] stated that, poor distribution and agglomeration MWCNT in the rubber matrix lead to poor electrical conductivity, and therefore after 
passing the percolation threshold (in this case $2.5 \%$ ), the conductivity of the MWCNT/HA latex composites reached an endpoint. On the other hand, it should be noted that, both HA and ENR latex films loaded AERODISP do not demonstrate antistatic property for the reason that AERODISP is a fume silica with no antistatic characteristic.

(A) HA latex films

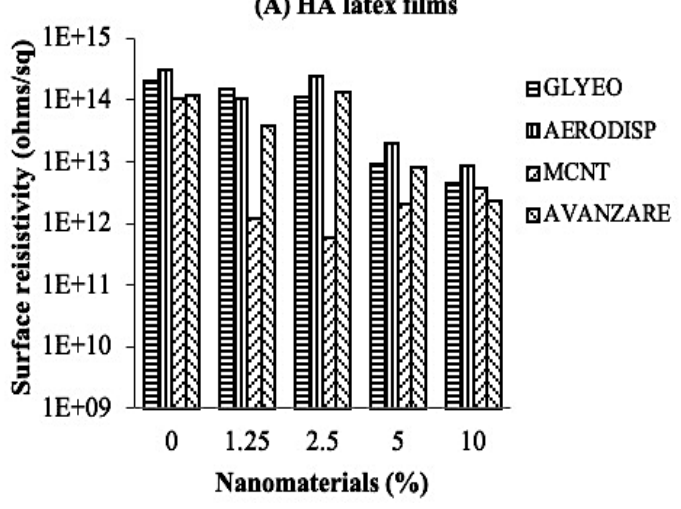

(B) ENR latex films

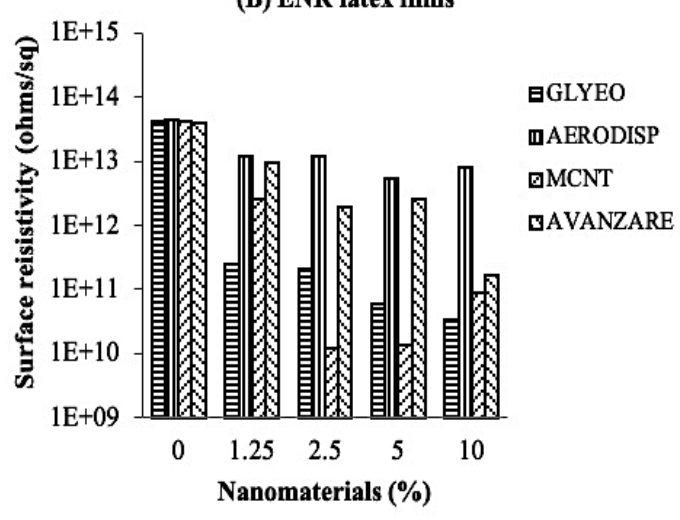

Figure 5: Surface resistivity value of HA and ENR latex films

Another research finding that should be disclosed in this article is the influence of chemical properties of ENR latex to nanomaterials used in this study that contribute to better electrical conductivity of the film. Previous study [26] stated that, high viscosity leads to poor distribution of nanomaterials in rubber matrix which lead to poor electrical conductivity of latex films. The present study agreed assumption made by the authors, however chemical properties of the material also play important roles. Referring to Table 3, the viscosity of ENR latex is much higher than HA latex but, electrical conductivity of ENR/nanomaterials latex films is much better than HA/nanomaterials latex films. Therefore, this study suggests that, the improvement of electrical conductivity of ENR/nanocomposites latex films compared to $\mathrm{HA} /$ nanocomposites latex films in this study, possibly due to the influence of polarity of ENR latex which improved compatibility between rubber particles and nanomaterial used in this study. Another reason could be due to the presence of surfactant in ENR latex system which helps better distribution of the nanomaterials in the ENR latex system during compounding process, thereby preventing rapid agglomerations of nanomaterials in the latex system.

\subsection{Volume resistivity}

Volume resistivity is the resistance to leakage current through the body of an insulating material. Volume resistivity is also called bulk resistivity because it is a measure of the resistivity across a defined thickness [23],[24]. A material is considered as antistatic material if volume resistivity greater than $1 \times 10^{4}$ $\Omega$-cm but less than $1 \times 10^{11} \Omega$-cm. This present work only focusses of volume resistivity of HA and ENR latex films loaded with GLYEO and MWCNT as both nanomaterials demonstrated exceptional antistatic property in surface resistivity measurement (Figure 5). This study found that, volume resistivity of ENR latex films filled with both GLYEO and MWCNT shows lower value compared to HA latex films (Figure 6).

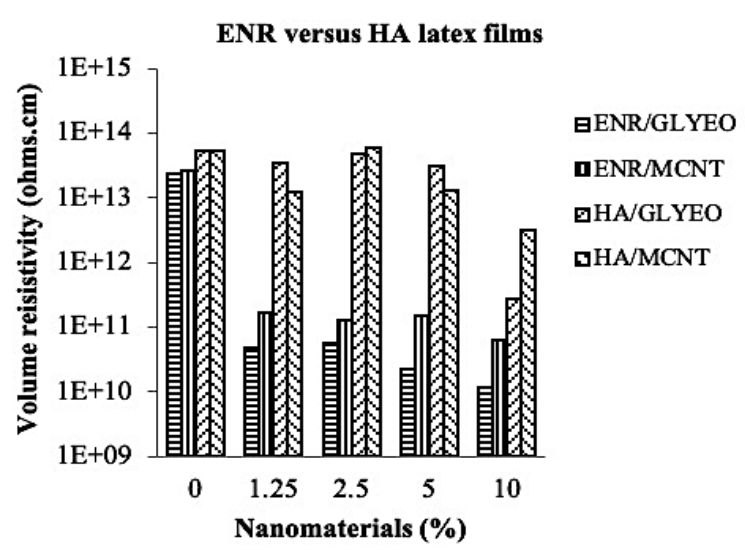

Figure 6: Volume resistivity value of HA and ENR latex films

The reason behind this finding is still not clear but could be due to the influence of epoxy group and the presence of surfactant in ENR latex helps better distribution of nanomaterials in the rubber matrix. However, only ENR latex film filled with GLYEO achieved antistatic property. The highest volume resistivity value was shown by EKOPRENA latex film filled with $10 \%$ of GLYEO, which is $1.15 \times 10^{\wedge} 10$ $\mathrm{ohm}-\mathrm{cm}$. This is unexpected result because MWCNT is a well-known conductive material, therefore it should impart higher improvement of electrical conductivity of latex films compared to other nanomaterials used in this study. Previous study [26] stated that, a well dispersed nanotubes that forming a continuous network structure certainly improves electrical conductivity of rubber materials. Therefore, inefficiency of MWCNT as conductive nanofiller in this study could be due poor dispersion and interface adhesion of MWCNT in the rubber matrix. 


\subsection{Morphological Structures}

To confirm assumption above, microscopy study was conducted. Figure 7 demonstrates the morphological structures of GLYEO and MWCNT filled ENR latex films. It can be seen that shows better dispersion compared to MWCNT.

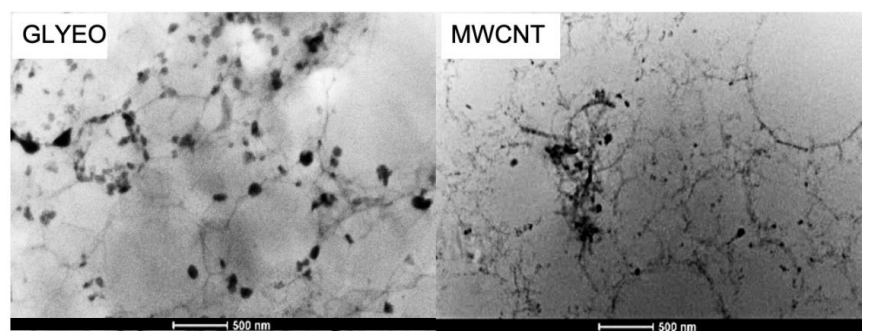

Figure 7: TEM micrographs of GLYEO and MWCNT in rubber matrix

Visualized at 5000 magnification (scale bar: $500 \mathrm{~nm}$ )

Figure 8 shows the agglomeration of MWCNT in the rubber matrix. Micrograph A visualized cylindrical structure of MWCNT used in this study. This micrograph also visualized the presence of impurities in the MWCNT dispersion. Micrograph B1 and B2 visualized individual MWCNT adhered to the elliptical shaped rubber particles at 5000 times magnification $(500 \mathrm{~nm})$ and 9900 times magnification (200 $\mathrm{nm}$ ) respectively. On the other hand, micrograph $\mathrm{C} 1$ and $\mathrm{C} 2$ confirmed the agglomeration of MWCNT in the rubber matrix. It is proven that, the poor electrical conductivity of MWCNT filled latex film is due to the poor distribution of this conductive nanomaterial. Therefore, further investigation should be conducted in the future studies to address this issue.

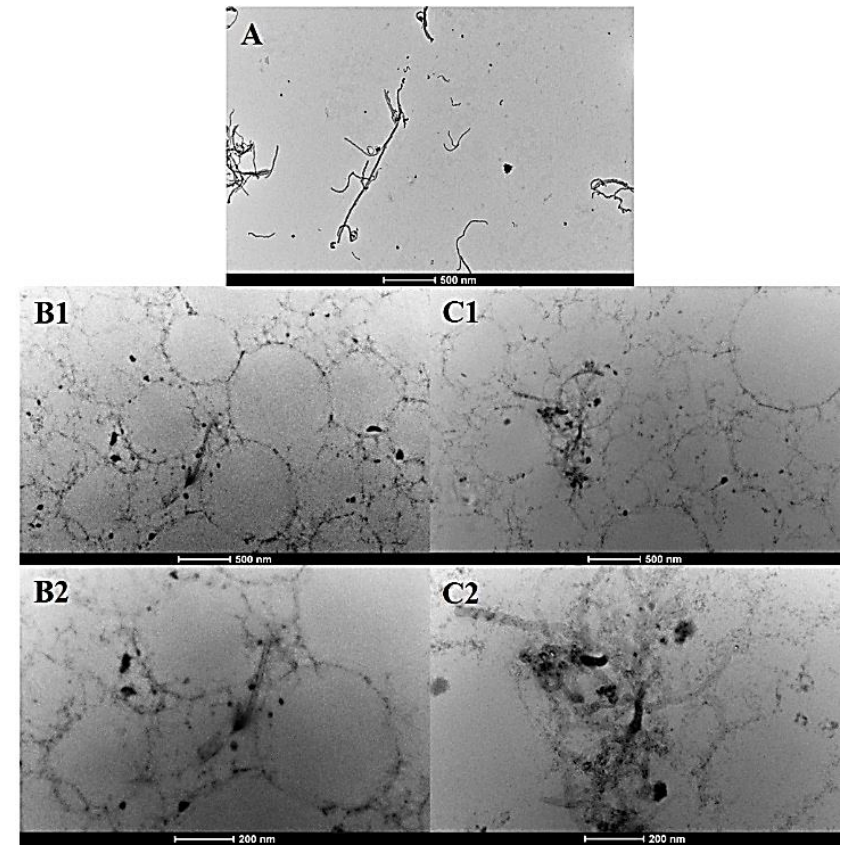

Figure 8: TEM micrographs of MWCNT filled latex film. A = MWCNT dispersion; $\mathrm{B} 1$ and $\mathrm{C} 1=$ MWCNT in rubber matrix visualized at 5000 magnification (scale bar: $500 \mathrm{~nm}$ ); B2 and $\mathrm{C} 2=$ MWCNT in rubber matrix visualized at 9900 magnification (scale bar: $200 \mathrm{~nm}$ ).

\subsection{Fabrication Shoe Soles}

Owing the fact that ENR is well-known material exhibits high-damping and excellent wet-grip properties, this could offer extra advantages for shoe soles made from ENR latex compared to normal NR and synthetic rubbers. The availability of concentrated ENR latex at $60 \%$ TSC has provided a better opportunity for using ENR in developing shoe soles. The high TSC of ENR lead to lower volume shrinkage compared to conventional TSC of ENR which is 30 $\%$ TSC. This study found that, the volume shrinkage of ENR latex film is approximately $10 \%$. The ENR latex also can be added with colour additive to offer variety colours of shoe soles (Figure 9).

This study observed that viscosity of ENR latex also plays an important role in fabricating shoe soles, whereas higher viscosity allows the latex to dry faster compared to low viscosity latex. In this work $150 \mathrm{ml}$ of ENR latex compound was poured into shoe soles mould. The ENR latex compound was left to dry overnight. On the other hand, HA latex compound requires 2-day to be dried. Figure 10 shows the prototype of shoe sole made from ENR latex. Nevertheless, overnight drying process to produce a pair of shoe soles is considered as craftsmanship technique. Therefore, further study to accelerate the drying process becoming focal point in future study. Successful development of accelerated drying process for shoe soles made from ENR latex can offer a better opportunity for large scale products manufacturing process. The presence of nanomaterials in the ENR latex composite help to improve strength and durability of the shoe soles. Further to that, there is a possibility of developing anti-static shoe soles from ENR latex composites due to anti-static property of the ENR latex film.

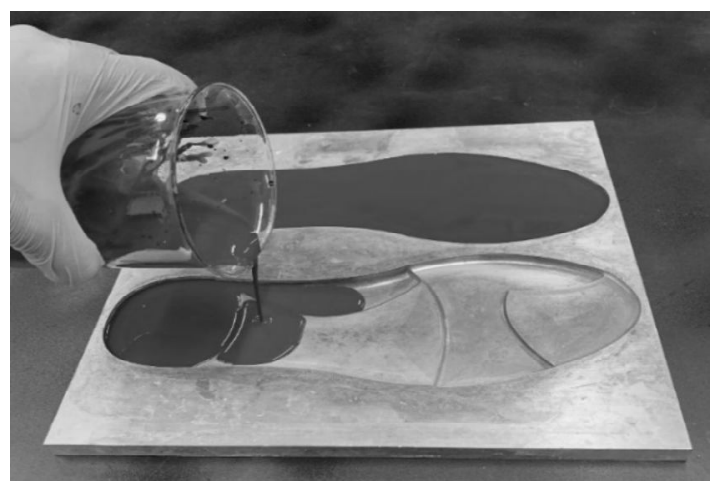

Figure 9: Fabrication of shoe soles made from ENR latex compound 


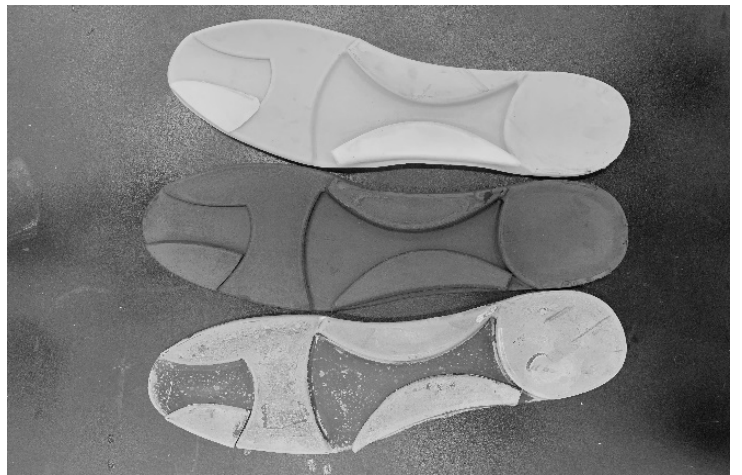

Figure 10: Prototype of shoe soles produced in this study.

\section{CONCLUSION}

This study revealed that, HA and ENR latex exhibit different characteristics when loaded with nanomaterials. Further to that, different types and levels of nanomaterials influenced crosslink density, physical properties and electrical conductivity of both HA and ENR latex films. This study also proved that ENR latex can be used to produce shoe soles.

\section{ACKNOWLEDGEMENT}

This study is part of a PhD study. The authors are grateful for the financial support and facilities provided by the Malaysian Rubber Board and the University of Nottingham. The authors also would like to thank to Ahmad Syaheer Abu Aswad, Hishamudin Samat, Suhaimi Ahmad and Mohd. Nizam Safie for their technical assistance during the duration of the study. The authors declare that there is no conflict of interest regarding the publication of this paper.

\section{REFERENCES}

1. D. C. Blackley. Polymer latices and technology. Volume 2: Types of latices (2nd ed.). London, U.K.: Chapman \& Hall, 1997.

2. R. Roslim. Characterizing physical properties and morphological structures of peroxide-vulcanized and sulphur-vulcanized natural rubber latex films. MSc. Thesis, Universiti Teknologi MARA, Malaysia, 2015.

3. R. Roslim, J. Jefri, J. S. Manroshan Singh and M. Y. Amir Hashim. Physical properties and fatigue lifecycles of natural rubber latex gloves. Advances in Environmental Biology, Vol. 8 No.8, pp 2714-2722, 2014.

4. J. J. Jacques and B. M. G. Lia. A study of material composition disclosure practices in green footwear products. Work, Vol. 41, pp 2101-2108, 2018.

5. P. Qianwen. Rubber in shoes : Role of technology and recycling based on a LCA analysis. MSc. Thesis, Politecnico Di Milano, Italy, 2017.

6. T. Staikos, R. Heath, B. Haworth, and S. Rahimifard. End-of-life management of shoes and the role of biodegradable materials. 13th CIRP International Conference on Life Cycle Engineering, 2006.
7. C. S. L. Baker, I. R. Gelling and R. Newell. Epoxidized natural rubber. Rubber Chemistry and Technology, Vol. 58, pp. 67-85, 1985.

8. A. Boonmahitthisud, S. Chuayjuljit, T. Nutchapong, and O. Saravari. Preparation and characterization of epoxidized natural rubber and epoxidized natural rubber/carboxylated styrene butadiene rubber blends. Journal of Metals, Materials and Minerals, Vol. 25 No. 1, pp 27-36, 2015.

9. S. P. Vernekar, M. B. Sabne, S. D. Patil, A. S. Patil, S. B. Idage, C. V. Avadhani, and S. Sivaram. Effect of latex concentration on epoxidation of natural rubber (NR) latex. Journal of Applied Polymer Science, Vol. 44 No. 12, pp 2107-2114, 1992.

10. M. Ahmad Khairul. An instrument for rapid method determination of rubber and non-rubber content in latex and solid rubber. Malaysian Rubber Technology and Development, Vol. 1, pp 14-16, 2016.

11. A. J. Durbateki and C. M. Miles. Near infrared and nuclear magnetic resonance spectrometry in analysis of butadiene polymers. Anal. Chem., Vol. 37, pp 1231-1235, 1965.

12. H. Fatin and H. C. Chin. Electronic applications of polymer electrolytes of epoxidized natural rubber and its composites. In Flexible and Stretchable Electronic Composites, pp. 37-59, 2016.

13. Malaysian Rubber Board. MRB In-house Test Method UPB/P/022-Determination of epoxidised level via proton nuclear magnetic resonance spectroscopy, 2017.

14. International Organization for Standardization. ISO 1652: Rubber latex - Determination of apparent viscosity by the Brookfield test method, 2011.

15. International Organization for Standardization. ISO 35: Natural rubber latex concentrate - Determination of mechanical stability time, 2004.

16. International Organization for Standardization. ISO 37: Rubber, vulcanized or thermoplastic-Determination of tensile stress-strain properties, 2017.

17. Internationl Organization for Standardization.ISO 14309: Rubber, vulcanized or thermoplastic Determination of volume and/or surface resistivity, 2011.

18. R. Roslim, K. S. Tan, and J. Jefri. Study on morphological structures and mechanical properties of natural rubber latex films prepared at different prevulcanisation and drying temperatures. Journal of Rubber Research, Vol. 21 No 1, pp 1-16, 2018.

19. D. Dazylah and M. S. Ma'zam. Vulcanisation and coagulant dipping of epoxidised natural rubber latex. Pertanika Journal of Science \& Technology, Vol. 18, pp 421-425, 2010.

20. R. Roslim and M. Y. Amir Hashim. Effect of filler on physical properties and surface morphology of natural rubber latex films. Journal of Rubber Research, Vol. 13 No. 2, pp 125-138, 2010.

21. K. L. Mok, H. M. Lim, K. S. Tan, R. Roslim, Y. Nurul Hayati, M. R. Fatimah Rubaizah and A. Azira. 
Performance of graphene in latexes via the conventional mixing route. 8th International Rubber Glove Conference \& Exhibition. Kuala Lumpur, Malaysia, 2016.

22. M. Y. Amir Hashim, R. Roslim, and M. W. Rosni. Physical properties and surface morphology of natural rubber latex films intended for seedling bag application. Journal Rubber Research, Vol. 15, No 4, pp 243-254, 2012.

23. N. González, A. Custal, S. Lalaouna, R. Riba, and E. Armelin. Improvement of dielectric properties of natural rubber by adding perovskite nanoparticles. European Polymer Journal, Vol. 75, pp 210-222, 2015.

24. T. Kuilla, S. Bhadra, D. H. Yao, N. H. Kim, S. Bose, and J. H. Lee. Recent advances in graphene based polymer composites. Progress in Polymer Science, Vol. 35, No. 11, pp 1350-1375, 2010.

25. W. N. E. Wan Mohd Noral Azman, J. Jaafar, W. N. W. Salleh, A. F. Ismail, M. H. D. Othman, M. A. Rahman, and $\mathrm{N}$. Yusof. Morphology effect on the selectivity of SPEEK/ENR membranes for direct methanol fuel cell. Materials Science Forum, Vol. 890, pp 267-273, 2017.

26. D. Firoozeh, and K. Maryam. A review of natural rubber nanocomposites based on carbon nanotubes. Journal of Rubber Research, Vol. 21, No. 4, pp 293-310, 2018.

27. H. Hasma. Proteins of natural rubberlatex concentrate. Journal of Natural Rubber Research, Vol. 7, No. 2, pp 102-112, 1992.

28. M. R. Fatimah Rubaizah, M. Y. Amir Hashim, Y. Nurul Hayati, A. Mohamad Asri, R. Roslim and A.B., R. Specialty latex material for sustainable product applications. 194th Technical Meeting International Elastomer Conference. Kentucky, USA, 2018. 